The University of Maine

\title{
DigitalCommons@UMaine
}

Maine-Syracuse Longitudinal Papers

Maine-Syracuse Longitudinal Study

2005

\section{Serum Cholesterol and Cognitive Performance in the Framingham Heart Study}

Penelope K. Elias

Merrill F. Elias

University of Maine - Main, mfelias@maine.edu

Ralph B. D'Agostino

Lisa M. Sullivan

Philip A. Wolf

Follow this and additional works at: https://digitalcommons.library.umaine.edu/

longitudinal_papers

Part of the Biochemical Phenomena, Metabolism, and Nutrition Commons, and the Cognitive Psychology Commons

\section{Repository Citation}

Elias PK, Elias MF, D'Agostino RB, Sullivan LM, Wolf PA. Serum cholesterol and cognitive performance in the Framingham heart study. 2005;67:24-30.

This Article is brought to you for free and open access by DigitalCommons@UMaine. It has been accepted for inclusion in Maine-Syracuse Longitudinal Papers by an authorized administrator of DigitalCommons@UMaine. For more information, please contact um.library.technical.services@maine.edu. 


\title{
Serum Cholesterol and Cognitive Performance in the Framingham Heart Study
}

Penelope K. Elias, PhD, Merrill F. Elias, PhD, Ralph B. D’Agostino, PhD, Lisa M. Sullivan, PhD, and Philip A. Wolf, MD

\begin{abstract}
Objective: The objective of this study was to examine the relationship between total cholesterol (TC) and cognitive performance within the context of the Framingham Heart Study, a large, community-based, prospective investigation of cardiovascular risk factors. Methods: Participants were 789 men and 1105 women from the Framingham Heart Study original cohort who were free of dementia and stroke and who received biennial TC determinations over a 16- to 18-year surveillance period. Cognitive tests were administered 4 to 6 years subsequent to the surveillance period and consisted of measures of learning, memory, attention/ concentration, abstract reasoning, concept formation, and organizational abilities. Statistical models were adjusted for multiple demographic and biological covariates. Results: There was a significant positive linear association between TC and measures of verbal fluency, attention/concentration, abstract reasoning, and a composite score measuring multiple cognitive domains. Performance levels for three clinically defined groups were examined. Participants with "desirable" TC levels $(<200 \mathrm{mg} / \mathrm{dL})$ performed less well than participants with borderline-high TC levels (200-239 mg/dL) and participants with high TC levels ( $\exists 240 \mathrm{mg} / \mathrm{dL})$. Conclusions: Lower naturally occurring TC levels are associated with poorer performance on cognitive measures, which place high demands on abstract reasoning, attention/concentration, word fluency, and executive functioning. Key words: total cholesterol, cognition, cardiovascular risk factors.
\end{abstract}

CVD = cardiovascular disease; $\mathbf{T C}=$ total cholesterol; $\mathbf{M A P}=$ mean arterial pressure; $\mathbf{B M I}=$ body mass index.

\section{INTRODUCTION}

A lthough a number of risk factors for cardiovascular disease (CVD) and stroke are related to lower cognitive functioning, eg, diabetes, obesity, and hypertension (1), the association between total serum cholesterol (TC) and cognition remains elusive. Both high and low TC have been related to deficits in cognitive performance. For example, low levels of TC (most frequently defined as $<200 \mathrm{~mm} / \mathrm{dL}$ or $<160$ $\mathrm{mm} / \mathrm{dL}$ ) have been associated with mild to severe cognitive deficit (2-6) and development of dementia (7). However, high levels of TC (usually defined as $>240 \mathrm{~mm} / \mathrm{dL}$ ) also have been associated with poorer cognitive test performance $(8-11)$.

Most studies concerned with TC and cognition have used brief tests of cognitive impairment such as the Mini-Mental State Examination and its variants $(3,5,7,12,15)$ or only a few outcome measures (2). Several studies have relied on composite scores from a battery of cognitive tests or clinical evaluation of cognitive impairment $(4,8-10)$. Because the major concern in these investigations was with overall poor cognition as defined by specific performance cutoffs, the relationship of TC and cognitive functioning within specific cognitive domains over a wide range of cognitive scores was not explored. Furthermore, many of the studies used only

From the Department of Mathematics and Statistics, Boston University, Boston, Massachusetts (P.K.E., M.F.E., R.B.D.); the Department of Biostatistics, Boston University School of Public Health, Boston, Massachusetts (L.M.S.); and the Department of Neurology, Boston University School of Medicine, Boston, Massachusetts (P.A.W.).

Address correspondence and reprint requests to Penelope K. Elias, PhD, Statistics and Consulting Unit, Department of Mathematics and Statistics, Boston University, 111 Cummington St., Boston, MA 02215. E-mail: pelias100@aol.com

Received for publication December 16, 2002; revision received August 17, 2004.

This research was supported by NHLBI's Framingham Heart Study (NHLBI/NIH Contract \# N01-25195), and Grants: NIA 5R01-AG 16495, NIA 5R01-AG08122, NIA 4RO1 HL65177, NINDS 5R01-NS17950, Boston University ADC P30 AG13846 and NHLBI 3RO1 HL67358.

DOI: 10.1097/01.psy.0000151745.67285.c2 clinic samples $(2,3,5,10-12)$ rather than community-based populations.

A few studies of TC and cognitive performance have involved tests designed to measure specific cognitive domains. Swan et al. (13) found that, among monozygotic twin pairs discordant for cognitive decline on the Digit Symbol Substitution test over a period of 5 years, the twins who declined in performance level exhibited significantly lower TC levels at the baseline assessment relative to the twins showing no decline. Using a choice reaction time task, Benton $(14,15)$ found that lower cholesterol values were associated with slower decision and movement times. Among females, the relationship between TC and cognitive measures was linear. Among males, however, both low and high cholesterol values were associated with slower decision times. Muldoon et al. $(16,17)$ administered cognitive tests from the Wechsler Adult Intelligence Scale reflecting both crystallized and fluid intelligence and found that cognitive performance decreased with increasing levels of TC for two measures of crystallized intelligence (information and vocabulary). For fluid intelligence (block design), performance was poorest at the lowest TC level and improved with increasing levels of TC. Finally, recent increases in TC levels have been found to be associated with better memory performance in healthy, middle-aged women (18).

The present study used the Framingham Heart Study original cohort, a large community-based sample for whom biennial physical examinations for multiple CVD risk factors, including TC, were conducted over a period of 28 years before cognitive testing. The availability of data on concomitant CVD risk factors and events during the surveillance period allowed these variables to be included as covariates in statistical models.

The following questions were addressed: 1) Is the relationship between TC and cognitive performance positive, so that higher TC levels are associated with better performance, or negative, so that higher TC levels are associated with poorer performance? 2) Are these relationships observed for multiple cognitive abilities or are they limited to specific cognitive domains? 3) Is the relationship between TC and cognitive 
performance modified with statistical control for concomitant CVD risk factors?

\section{METHODS Subjects}

The initial pool of study participants included 2123 males and females in the Framingham Heart Study, aged 55 to 88 years, who were administered a battery of neuropsychologic tests (19) during their $14^{\text {th }}$ or $15^{\text {th }}$ biennial examination (1974-1978). All subjects had been assessed for cardiovascular and cerebrovascular disease events and risk factors by physician examination on a biennial schedule from 1948 to the time of neuropsychologic testing.

The surveillance window for measurement of TC extended from examinations 4 through 12, and thus it preceded neuropsychologic testing by 4 to 6 years. Of the 2123 eligible participants, 229 people were excluded based on the following criteria as determined at the time of neuropsychologic testing: 1) failure to attend examination 4 (baseline measurement, to assure that early measures of TC and covariates were included for every participant; $n=87$ ); 2) attendance at fewer than six examinations (to assure that an adequate sampling of TC measurements was available for every participant; $n=36$ ); 3 ) history of completed stroke $(n=78)$; and 4$)$ history of dementia $(n=28)$. The final sample consisted of 789 men and 1105 women.

\section{Total Serum Cholesterol}

The methods for determination of total serum cholesterol (in milligrams per deciliter) have been described previously (20). TC determinations were made at each examination during the surveillance period. Multiple measures of TC are important in determining long-term TC levels because previous studies have shown that considerable intraindividual variation over time is common $(21,22)$. Thus, a minimum of six and a maximum of nine measurements were available for each subject. Mean TC levels were calculated by summing the values for each examination and dividing by the number of examinations attended.

In addition to treating mean TC values as a continuous variable in multiple regression analyses described subsequently, the mean values were classified into 3 clinically relevant categories: 1) $<200 \mathrm{mg} / \mathrm{dL}$, 2) 200 to $239 \mathrm{mg} / \mathrm{dL}$, and 3) $\geq 240 \mathrm{mg} / \mathrm{dL}$. These TC categories are described as "desirable," "borderline-high," and "high" by the National Cholesterol Education Program Expert Panel (23). Ranges for the low and high TC categories in our sample were 150 to 199 and 240 to $380 \mathrm{mg} / \mathrm{dL}$, respectively. These categories were chosen for describing the association between TC and cognitive performance because they provide a clinical frame of reference.

\section{Covariates}

Demographic covariates included age (years), maximum education level attained, and highest occupational level attained. The demographic covariates were determined at the time of cognitive testing.

Additional data on concomitant CVD risk factors and TC-related variables were used to create a set of biologic covariates. CVD risk factor variables were calculated from data obtained during the same surveillance window used for the determination of TC and consisted of the following: 1) mean arterial pressure (MAP), calculated as (diastolic blood pressure + [systolic blood pressure - diastolic blood pressure]/3); 2) body mass index (BMI), calculated as weight $(\mathrm{kg}) /$ height $\left.(\mathrm{m})^{2} ; 3\right)$ self-reported number of cigarettes smoked per day; and 4) self-reported number of alcoholic beverages consumed per week, converted to ounces of alcohol consumed per week. A mean score for each variable was calculated by summing the values obtained during the surveillance window and dividing by the number of examinations attended. A fifth risk factor covariate was presence or absence of a diagnosis of type II diabetes determined by 1) age greater than 30 years at time of diagnosis, 2) treatment with insulin or oral hypoglycemic agents, or 3) a casual blood glucose level $>8.3 \mathrm{mmol} / \mathrm{L}$. A person was defined as diabetic if the criteria were met during the surveillance period. Finally, a diagnosis of CVD before or concurrent with cognitive testing constituted a sixth covariate coded as present (1) or absent (0).

Two TC-related covariates were created based on studies indicating that they may also have potential relationships to cognitive functioning (24-26): self-reported use of cholesterol-lowering medication and self-reported adherence to a cholesterol-lowering diet. These covariates were coded as present/ absent at the time of neuropsychologic testing and were included in the biologic covariate model. Lastly, because many medications are known to have cognitive side effects, medications in use at the time of cognitive testing were grouped into three categories and coded as present/absent for each category: cardiovascular drugs (including antihypertensive drugs, anticoagulants, antiangina drugs, and so on), psychotropic drugs (including tranquilizers and sleeping aids), and a general category including all other medications. These three additional variables were added to the biologic covariate set. Distributional properties of the demographic and biologic covariate sets are shown in Table 1.

\section{Cognitive Test Battery}

The cognitive test battery included eight subtests from the Wechsler Adult Intelligence Scale, the Wechsler Memory Scale, and the Multilingual Aphasia Examination (19). The subtests measure verbal memory and learning, visual organization and memory, attention and concentration, abstract reasoning, concept formation, and organizational abilities (27). Administration time for this battery was 30 to 45 minutes and subtests were given in the following sequence: logical memory-immediate recall, visual reproductions, paired associates learning, digit span forward, digit span backward, word fluency (controlled oral word associations), similarities, and logical memory-delayed recall. Normative test data for the cognitive measures, including norms for various age and education categories, have been published for the Framingham Study participants (19).

Based on an earlier factor analysis of the cognitive test battery (19), two composite score variables were constructed. The first composite, labeled learning/memory, reflects learning of new verbal and visual material with an emphasis on secondary memory processes. It consists of logical memoryimmediate recall, visual reproductions, and paired associates, all equally weighted. The second composite, labeled attention/concentration, reflects memory for digits (presented orally), but also attention, passive span of apprehension, and concentration, specifically, "double-tracking," which requires simultaneous working memory and reversing operations (27). It consists of digit span forward and digit span backward, again, equally weighted.

Because one primary purpose of this study was to ascertain whether TC levels affected specific cognitive domains, we limited reporting of data to those cognitive measures reflecting relatively independent abilities. Thus, the set of measures relevant to our purpose consists of 1) the learning/memory composite; 2) the attention/concentration composite; 3) similarities, a measure of abstract reasoning and concept formation; and 4) word fluency, a measure of executive functioning and organization. Finally, a total composite score, representing overall cognitive performance, was constructed by summing the 4 cognitive measures. This score served as a protection scheme against possible unreliability of individual test measures and spurious statistically significant findings resulting from use of multiple cognitive measures.

\section{Statistical Methods}

Preliminary analyses were conducted to evaluate the relationship of the continuous distribution of TC values to each cognitive performance measure. For these analyses, the mean TC distribution was log-transformed $\left({ }_{\ln } \mathrm{TC}\right)$ to normalize the distribution. Linear and quadratic ${ }_{\ln } \mathrm{TC}$ terms were entered hierarchically into two models defined by covariates. In a basic model, age, gender, education level, and occupation level were included as demographic covariates, along with the ${ }_{\ln } \mathrm{TC}$ variable. In a biologic covariate model, the following variables were added to the basic model: mean arterial pressure, BMI, cigarette smoking, alcohol consumption, history of diabetes, history of CVD, use of cholesterol-lowering drugs, adherence to a cholesterol-lowering diet, and use of psychotropic, cardiovascular, or other drugs.

The main analyses of clinical TC categories followed the same analytic strategy of basic and biologic covariate models as the preliminary analyses. The three TC groups were entered into the general linear models as an ordinal class variable (28).

Two sets of secondary analyses were conducted. First, because previous studies presented the possibility that poorer cognition is associated with very 
TABLE 1. Demographic and Covariate Information by Total Cholesterol Group for the Framingham Heart Study Sample $(N=1894)$ Who Participated in Cognitive Testing at Examinations 14 or 15

\begin{tabular}{|c|c|c|c|c|c|c|c|}
\hline & \multicolumn{2}{|c|}{$\begin{array}{l}\text { TC }<200 \\
(n=248)\end{array}$} & \multicolumn{2}{|c|}{$\begin{array}{l}\text { TC } 200 \text { to } 239 \\
(n=681)\end{array}$} & \multicolumn{2}{|c|}{$\begin{array}{l}\mathrm{TC} \geq 240 \\
(n=965)\end{array}$} & \multirow[t]{2}{*}{$p<\dagger$} \\
\hline & Mean & $\mathrm{SD}^{*}$ & Mean & $S D^{*}$ & Mean & $\mathrm{SD}^{*}$ & \\
\hline Age (years) & 63.6 & 6.5 & 66.4 & 7.2 & 69.0 & 7.5 & 0.01 \\
\hline Education $\ddagger$ & 4.8 & 1.6 & 4.8 & 1.6 & 4.7 & 1.7 & NS \\
\hline Occupation§ & 4.2 & 1.5 & 4.0 & 1.6 & 4.0 & 1.6 & NS \\
\hline Cigarettes/day & 7.7 & 10.8 & 9.2 & 11.8 & 6.6 & 9.8 & 0.01 \\
\hline Alcohol (ounces/wk) & 3.6 & 5.5 & 4.3 & 5.4 & 3.7 & 5.4 & 0.04 \\
\hline Body mass index & 25.3 & 4.0 & 25.6 & 3.6 & 26.1 & 3.8 & 0.01 \\
\hline \multirow[t]{2}{*}{ Mean arterial pressure } & 96.2 & 10.2 & 97.3 & 10.4 & 101.0 & 10.8 & 0.01 \\
\hline & No. & Percent & No. & Percent & No. & Percent & \\
\hline Female & 139 & 56.1 & 340 & 50.1 & 623 & 64.6 & 0.01 \\
\hline Diabetes & 17 & 6.9 & 56 & 8.2 & 93 & 4.9 & NS \\
\hline Cardiovascular disease & 26 & 10.5 & 108 & 15.9 & 222 & 23.0 & 0.01 \\
\hline Cholesterol-lowering diet & 4 & 1.6 & 19 & 2.8 & 69 & 7.2 & 0.01 \\
\hline Cholesterol-lowering drugs & 1 & 0.4 & 4 & 0.6 & 34 & 3.5 & 0.01 \\
\hline Cardiovascular drugs & 65 & 26.2 & 203 & 29.8 & 409 & 42.4 & 0.01 \\
\hline Psychotropic drugs & 21 & 8.5 & 77 & 11.3 & 102 & 10.6 & NS \\
\hline Other drugs & 110 & 44.4 & 333 & 48.9 & 488 & 50.6 & NS \\
\hline
\end{tabular}

*Standard deviation.

$\dagger$ Significance levels for overall differences among TC groups: $F$ tests for continuous variables; chi-squared tests for categorical variables; NS = nonsignificant. Education was measured on a scale of 0 to 8 in which 0 represented no years of formal schooling and 8 represented postgraduate levels.

§Occupation was measured on a scale of 1 to 7 in which 1 represented executive/professional occupations and 7 represented unskilled labor.

high and/or low TC values, each of the "desirable" and "high" TC categories were split into two groups, and five-group analyses were conducted using the same models as for the three-group analyses. Although the five-group analyses provide additional information about the extremes of the cholesterol distribution as presented in our sample, they are less powerful in terms of smaller $n$ 's in the very high and low TC groups and are not directly applicable to currently accepted clinical TC categories.

Second, the surveillance period was redefined as concurrent with cognitive testing, thus allowing for a cross-sectional analysis of the TC-cognition relationship at examinations $14 / 15$. These data were subjected to the same statistical procedures described previously.

\section{RESULTS}

In Table 1, demographic and covariate data are displayed by TC group. The mean TC values $( \pm$ standard deviation [SD]) for each TC group were: 1) $185.0 \pm 11.0,2) 221.2 \pm$ 11.2, and 3) $272.5 \pm 26.8$. Age increased from the lowest to highest cholesterol group. The middle TC group smoked the most cigarettes/day and consumed the most alcohol. As might be expected, higher BMI and MAP, greater use of cardiovascular and cholesterol-lowering medications, adherence to a cholesterol-lowering diet, and higher prevalence of CVD were all characteristic of the highest TC group.

Using the basic model described previously, a preliminary analysis was conducted to determine if there was a significant gender $\times$ TC interaction. The interaction term was nonsignificant for all cognitive test variables ( $p$ range $=0.22-0.85$ ). Thus, a main effects model, including gender, was used for all subsequent analyses.

\section{Preliminary Analyses: The Continuous Total Cholesterol Distribution}

Results were the same for the basic and biological covariate models. The quadratic term failed to reach statistical significance for all of the cognitive measures. The linear ${ }_{\ln } \mathrm{TC}$ term was significant for the following variables: similarities $(p<.03)$, word fluency $(p<.002)$, attention/concentration $(p<.03)$, and the total composite $(p<.02)$. In all analyses, ${ }_{1 n} \mathrm{TC}$ was positively related to the scores on the cognitive variables, ie, lower ${ }_{1 \mathrm{n}} \mathrm{TC}$ levels were associated with poorer cognitive performance. The pattern of significant results was the same when this analysis was repeated with the untransformed TC scores.

\section{Total Cholesterol Clinical Categories}

Covariate-adjusted group means, standard errors of the mean (SE), overall $F$ tests of the TC variable, and results of pairwise $t$ tests between TC groups are shown in Table 2 . Again, results were essentially identical for the basic and biologic risk factor models; consequently, the findings presented subsequently are for the biologic risk factor model. As can be seen in Table 2, the low TC group performed more poorly on similarities, word fluency, attention/concentration, and the total composite. However, for similarities, the overall test of significance as not statistically significant $(p=.08)$. The total composite scores were transformed to $z$-scores (mean $=0, \mathrm{SD}=1)$ to meaningfully evaluate the statistical group differences. Thus, as can be seen in the bottom row of Table 2, the low TC group performed $0.10 \mathrm{SD}$ below the mean of the sample and $0.18 \mathrm{SD}$ below the high TC group.

Although adjusted raw score differences between groups are relatively small, the finding of poorer performance by the low TC group is consistent with previous studies demonstrating similar results. In terms of cardiovascular risk, this group is considered to have cholesterol levels in the "desirable" range. To describe their cognitive risk in epidemiologic terms, we performed logistic regression analyses with the highest TC 
TABLE 2. Adjusted Means (z Scores) and Standard Errors of the Mean (SE) by Three Total Cholesterol (TC) Groups for the Neuropsychologic Tests and the Total Composite Score*

\begin{tabular}{|c|c|c|c|c|c|c|c|c|}
\hline & \multicolumn{2}{|c|}{ Group 1} & \multicolumn{2}{|c|}{ Group 2} & \multicolumn{2}{|c|}{ Group 3} & \multirow[b]{2}{*}{$\begin{array}{l}\text { Overall TC } \\
\text { group test }\end{array}$} & \multirow[b]{2}{*}{$\begin{array}{l}\text { Group } \\
\text { contrasts }\end{array}$} \\
\hline & \multicolumn{2}{|c|}{$\begin{array}{c}\mathrm{TC}=150 \text { to } 199 \\
(n=248)\end{array}$} & \multicolumn{2}{|c|}{$\begin{array}{c}\mathrm{TC}=200 \text { to } 240 \\
(n=681)\end{array}$} & \multicolumn{2}{|c|}{$\begin{array}{c}\mathrm{TC}=240 \text { to } 380 \\
(n=965)\end{array}$} & & \\
\hline & Mean & SE & Mean & SE & Mean & SE & $p<$ & $p<.05$ \\
\hline Similarities & 11.19 & 0.29 & 11.89 & 0.17 & 11.90 & 0.15 & 0.08 & $1<2,3$ \\
\hline Word fluency & 29.40 & 0.70 & 31.68 & 0.42 & 32.20 & 0.37 & 0.002 & $1<2,3$ \\
\hline Learning/memory & 8.42 & 0.14 & 8.60 & 0.08 & 8.35 & 0.07 & NS & \\
\hline Attention/concentration & 4.85 & 0.06 & 4.98 & 0.04 & 5.04 & 0.03 & 0.01 & $1<3$ \\
\hline Total composite & 53.92 & 0.94 & 56.90 & 0.56 & 57.36 & 0.50 & 0.01 & $1<2,3$ \\
\hline Total composite (z scores) & -0.10 & 0.05 & 0.06 & 0.03 & 0.08 & 0.01 & 0.01 & $1<2,3$ \\
\hline
\end{tabular}

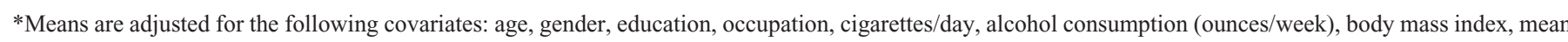

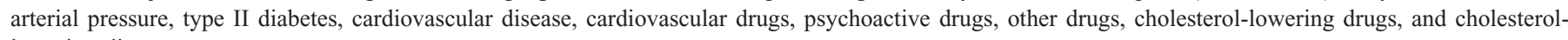
lowering diet.

group as the referent and determined the odds ratios for the two lower TC group relative to the highest TC group. Specifically, we estimated the odds of performing in the lower $33^{\text {rd }}$ percentile (poor performance) and the lower $10^{\text {th }}$ percentile (very poor performance) of the full distribution of test scores. The odds ratios for the middle TC group (relative to the high TC group) were statistically nonsignificant (all $p$ 's $>0.10$ ). Odds ratios for the low TC group (relative to the high TC group) are shown in Table 3.

\section{Secondary Analyses}

As described previously, the high and low TC categories were each split into two groups, and five-group analyses, identical to the three-group analyses, were conducted. The two lower TC groups had mean TC levels of $171.0 \pm 6.8$ and $190.8 \pm 6.0$. The two higher TC groups had mean TC levels of $263.4 \pm 16.6$ and $321.5 \pm 18.3$. Results of the five-group analyses are presented in Table 4.

Like with the three-group analyses, overall significant group differences were observed for word fluency $(p<.003)$, the attention/concentration composite $(p<.02)$, and the total composite $(p<.01)$. As can be seen in Table 4 , the relationship between TC groups and word fluency exhibits a nearly linear trend across groups, with the lowest TC group performing most poorly and the highest TC group performing best.
The results for attention/concentration and the total composite are characterized primarily by poorer performance in the lowest TC group relative to the three highest groups. For the total composite, the lowest TC group performed $0.22 \mathrm{SD}$ below the mean and 0.39 SD below the highest TC group.

When the TC surveillance window was defined as concurrent with cognitive testing (examinations 14/15) and the original three-group TC analyses conducted, a similar pattern of results was obtained, although the overall $F$ test of differences among TC groups was not significant for similarities and attention/concentration. However, the results for word fluency and the total composite were statistically significant ( $p$ 's $<0.002$ and 0.01 , respectively), with the low TC group performing more poorly than the middle and high TC groups for both variables $(p$ 's $<0.05)$.

\section{DISCUSSION}

The present study used a large, prospective, communitybased sample of men and women who were free of stroke and dementia up to the time of cognitive testing. The TC surveillance period made use of an average of multiple TC determinations, and thus the potential unreliability of a single measurement was avoided. Extensive information regarding CVD risk factors and events concurrent with TC measurements was

TABLE 3. Odds Ratios (and 95\% Confidence Limits [CLs]) for Poorer Performance by Low Total Cholesterol Group (<200 mg/dL) Relative to the High Total Cholesterol Group ( $\geq 240 \mathrm{mg} / \mathrm{dL}$ )*

\begin{tabular}{|c|c|c|c|c|c|c|}
\hline & \multicolumn{3}{|c|}{$\begin{array}{l}\text { Performance Below the } \\
33^{\text {rd }} \text { Percentile }\end{array}$} & \multicolumn{3}{|c|}{$\begin{array}{l}\text { Performance Below the } \\
10^{\text {th }} \text { Percentile }\end{array}$} \\
\hline & Odds ratio & $95 \% \mathrm{CL}$ & $p<$ & Odds ratio & $95 \% \mathrm{CL}$ & $p<$ \\
\hline Similarities & 1.46 & $1.00-2.12$ & .06 & 2.17 & $1.22-3.87$ & .01 \\
\hline Word fluency & 1.76 & $1.25-2.49$ & .002 & 1.84 & $1.09-3.08$ & .02 \\
\hline Attention/concentration & 1.45 & $1.01-2.10$ & .06 & 2.24 & $1.38-3.61$ & .004 \\
\hline Total composite & 1.49 & $1.02-2.18$ & .03 & 1.80 & $1.01-3.18$ & .03 \\
\hline
\end{tabular}

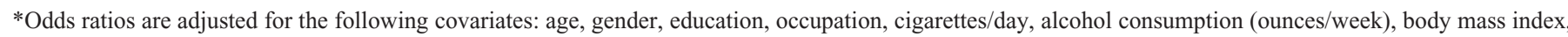

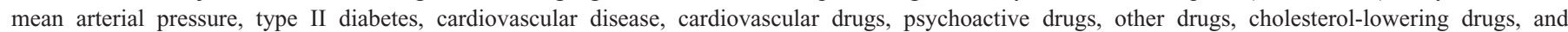
cholesterol-lowering diet. 
TABLE 4 . Adjusted Means ( $z$ Scores) and Standard Errors of the Mean (SE) by Five Total Cholesterol (TC) Groups for the Neuropsychologic Tests and the Total Composite Score*

\begin{tabular}{|c|c|c|c|c|c|c|c|c|c|c|c|}
\hline & \multicolumn{2}{|c|}{ Group 1} & \multicolumn{2}{|c|}{ Group 2} & \multicolumn{2}{|c|}{ Group 3} & \multicolumn{2}{|c|}{ Group 4} & \multicolumn{2}{|c|}{ Group 5} & \multirow{3}{*}{$\begin{array}{c}\text { Group } \\
\text { contrasts } \\
p<.05\end{array}$} \\
\hline & \multicolumn{2}{|c|}{$\begin{array}{c}\mathrm{TC}=150 \text { to } 179 \\
(n=72)\end{array}$} & \multicolumn{2}{|c|}{$\begin{array}{c}\mathrm{TC}=180 \text { to } 199 \\
(n=176)\end{array}$} & \multicolumn{2}{|c|}{$\begin{array}{c}\mathrm{TC}=200 \text { to } 239 \\
(n=681)\end{array}$} & \multicolumn{2}{|c|}{$\begin{array}{c}\mathrm{TC}=240 \text { to } 299 \\
(n=819)\end{array}$} & \multicolumn{2}{|c|}{$\begin{array}{c}\mathrm{TC}=300 \text { to } 380 \\
(n=146)\end{array}$} & \\
\hline & Mean & SE & Mean & SE & Mean & SE & Mean & SE & Mean & SE & \\
\hline Similarities & 11.41 & 0.52 & 11.09 & 0.35 & 11.88 & 0.17 & 11.85 & 0.16 & 12.21 & 0.39 & NS \\
\hline Word fluency & 28.42 & 1.26 & 29.80 & 0.83 & 31.66 & 0.42 & 31.98 & 0.39 & 33.71 & 0.94 & $\begin{array}{c}1,2<3,4,5 \\
3<5\end{array}$ \\
\hline Learning/memory & 8.15 & 0.25 & 8.53 & 0.17 & 8.60 & 0.08 & 8.35 & 0.08 & 8.38 & 0.19 & NS \\
\hline Attention/concentration & 4.70 & 0.12 & 4.91 & 0.07 & 4.98 & 0.04 & 5.03 & 0.04 & 5.15 & 0.09 & $1<3,4,52<5$ \\
\hline Total composite & 51.82 & 1.70 & 54.75 & 1.12 & 56.89 & 0.56 & 57.12 & 0.53 & 59.06 & 1.29 & $1<3,4,52<5$ \\
\hline Total Composite (z scores) & -0.22 & 0.09 & -0.06 & 0.06 & 0.06 & 0.03 & 0.07 & 0.03 & 0.17 & 0.07 & $1<3,4,52<5$ \\
\hline
\end{tabular}

*Means are adjusted for the following covariates: age, gender, education, occupation, cigarettes/day, alcohol consumption (ounces/week), body mass index, mean arterial pressure, type II diabetes, cardiovascular disease, cardiovascular drugs, psychoactive drugs, other drugs, cholesterol-lowering drugs, and cholesterollowering diet.

available, allowing for statistical adjustment for these factors in multivariable models.

The large sample size used in this study is a strength, but it is particularly important to determine whether the relations between TC and cognitive performance are important as well as statistically significant. Adjusted for multiple demographic and cardiovascular risk factors, the difference between means for the lowest TC group and the highest TC group for the total composite score, expressed in $\mathrm{Z}$ scores (units of SD) was 0.39 (Table 4). This relationship might not be considered important in clinical practice. However, with regard to the population as a whole, a relationship of this size is very likely significant in epidemiologic (population) terms as is indicated by the increase in risk for poor performance expressed by the odds ratios shown in Table 3.

Consistent with studies demonstrating poorer cognitive performance for lower TC levels, we found that earlier low TC levels were predictive of poorer performance for similarities, word fluency, attention/concentration, and overall cognitive performance, as measured by the total composite. This was especially evident among people with TC levels lower than $180 \mathrm{mg} / \mathrm{dL}$. Similar results were shown when TC was measured at the time of cognitive testing, although findings for attention/concentration and similarities were no longer significant. It should be noted that the effects of longitudinally measured TC on these specific cognitive measures were generally small in terms of raw score differences (see Table 2), and the lack of significant episodic findings may be related to the unreliability of the single available TC measurement $(21,22)$, thus reducing the probability of detecting small differences.

Two of the cognitive variables most strongly associated with TC, ie, the attention/concentration composite and word fluency, place demands on executive functioning processes $(29,30)$. In this regard, it is important to note that tests measuring speed of mental processing (3-15) and fluid intelligence $(16,17)$ have shown positive linear relationships with TC in previous studies. Executive abilities and speed of men- tal processing have been shown to account for a significant amount of the variance in fluid intelligence among cognitively normal adults (31). Consequently, demands on executive functioning may be one common feature of cognitive outcome measures for which low TC is related to poorer performance.

The adverse effects of low TC on cognitive performance have been reported in previous studies (13-17), and these effects have biologic plausibility. Low cholesterol levels may accompany chronic diseases, poor intake or absorption of nutrients, and diagnosed and occult malignancies (32), which in turn may be associated with poorer cognitive performance. Low serum cholesterol and poorer cognitive functioning may be related because neuronal cells require TC for normal metabolic processes (16). Furthermore, the interaction between plasma cholesterol concentrations, cholesterol present in cell membranes, and serotonergic activity is complex and may account for the negative cognitive effects of low TC (33). Although the "cholesterol-serotonin" hypothesis has been advanced to explain the associations among low TC, violent behavior, and suicide (33), it is possible that adverse modulating effects of low TC on serotonergic activity may extend to the role of serotonin in cognitive processes as well (34).

Findings in this study are inconsistent with the set of previous studies finding a negative association between TC and cognitive performance (9-12). However, the lack of consistency between the present findings and those studies reporting a high TC-poor performance relationship may be the result of differences in methodology. The present study used the mean of biennial TC measurements obtained over a period of 16 to 18 years and multiple demographic and cardiovascular risk factor control variables. Thus, it was possible to achieve greater statistical control for those risk factors commonly associated with high TC levels, eg, obesity and/or higher blood pressures, both of which have been found to be predictive of poorer cognitive function (35). Finally, it should be noted the nonsignificant results for our learning/memory composite are consistent with Teunissen et al. (36) who found no baseline or longitudinal relations between TC and perfor- 
mance on the Auditory Verbal Learning Test, which includes a memory component.

It is important to note that treatment for high $\mathrm{TC}$ was not common or particularly effective during the period of this study, at least by standards achieved today. None of our participants were being treated with currently popular and highly effective regimens for lowering cholesterol. Furthermore, the prevalence of any cholesterol treatment was low, and we adjusted for anticholesterol drug treatment and diet. Thus, our data do not address the consequences of reducing TC to "desirable" levels by statins or other new cholesterollowering medications. Naturally low cholesterol and cholesterol levels lowered by successful treatment may have very different implications for cognitive functioning. Moreover, competing risks must always be taken into consideration. Lower cholesterol values may have modestly detrimental effects on cognitive function for the individual but, depending on the patient's risk profile, may have beneficial effects with respect to cardiovascular morbidity and mortality.

\section{Study Limitations}

This study did not include longitudinal assessment of cognitive performance. The lack of baseline cognitive measures prevented an evaluation of whether initial cognitive differences associated with TC levels are the actual determinant of cognitive performance outcomes at examinations $14 / 15$. Thus, we cannot eliminate the possibility that early TC levels were related to change in performance over time or that low TC was actually associated with poorer performance at a younger age. Similarly, we cannot specify a causal relationship between TC levels and cognitive performance.

Total cholesterol may be a marker for specific biologic (eg, serotonin, APOE genotype $(16,37)$ ) and/or psychologic (eg, type A behavior, depression) variables, which themselves are directly related to cognitive outcomes, but which were not included in the present study. However, with regard to the influence of psychologic variables on cognition in the Framingham Study cohort, Haynes et al. (38) found that very few personality or psychosocial traits were concurrently related to serum cholesterol levels at examinations 8/9. From among 20 psychosocial variables assessed, several significant associations were found, but primarily within specific subgroups. Thus, it is unlikely that psychosocial variables commonly associated with CVD risk would account for our findings.

The psychosocial scales used by Haynes et al. (38) did not include any measures of depression, nor did the present study. Low TC has been associated with depressed mood and clinical depression $(39,40)$, although not all studies report this relationship (41-43). Nonetheless, depression has been linked to both dementia and cognitive decline (44), including poorer performance on tasks requiring executive functioning and verbal and nonverbal memory (45). It is possible that early measures of depression may be associated with later cognitive performance, and it is even more likely that this would be true of persistent, long-term depression. Clearly, further studies are needed to evaluate the relationships among TC, depression, and cognition.

\section{CONCLUSIONS}

Low concentrations of naturally occurring total serum cholesterol, including those levels in the currently defined "desirable" range, were associated with poorer cognitive performance, especially for those tests that place strong demands on executive function and an overall measure of cognitive performance. Hopefully, the present study will stimulate further research designed to elucidate the mechanisms underlying relationships between naturally lower cholesterol and lowered cognitive functioning.

\section{REFERENCES}

1. Elias MF, Elias PK, Robbins MA, Wolf PA, D’Agostino RB. Cardiovascular risk factors and cognitive functioning: an epidemiological perspective. In: Waldstein SR, Elias MF, eds. Neuropsychology of Cardiovascular Disease. Mahwah, NJ; 2001:83-104.

2. Cattin, L, Bordin P, Fonda M, Adamo C, Barbone F, Bovenzi M, Manto A, Pedrone C, Pahor M. Factors associated with cognitive impairment among older Italian inpatients. J Am Geriatr Soc 1997;45:1324-30.

3. Ranieri P, Rozzini R, Franzoni S, Barbisoni P, Trabucchi M. Serum cholesterol levels as a measure of frailty in elderly patients. Exp Aging Res 1998;24:169-79.

4. Reuben DB, Ix JH, Greendale GA, Seeman TE. The predictive value of combined hypoalbuminemia and hypocholesterolemia in high functioning community-dwelling older persons: MacArthur Studies of Successful Aging. J Am Geriatr Soc 1999;47:402-6.

5. Stump TE, Callahan CM, Hendrie HC. Cognitive impairment and mortality in older primary care patients. J Am Geriatr Soc 2001;49:934-40.

6. Wada T, Matsubayashi K, Okumiya K, Kimura S, Osaka Y, Doi Y, Ozawa T. Lower serum cholesterol level and later decline in cognitive function in older people living in the community, Japan. J Am Geriatr Soc 1997;45:1411-2.

7. Piquet O, Grayson DA, Creasey H, Bennett HP, Brooks WS, Waite LM, Broe GA. Vascular risk factors, cognition and dementia incidence over 6 years in the Sydney Older Persons Study. Neuroepidemiology 2003;22: $165-71$.

8. Desmond DQ, Tatemichi TK, Paik M, Stern Y. Risk factors for cerebrovascular disease as correlates of cognitive function in a stroke-free cohort. Arch Neurol 1993;50:162-6.

9. Kivipelto M, Helkala E-L, Hänninen T, Laakso MP, Hallikainen M, Alhainen K, Soininen H, Tuomilehto J, Nissinen A. Midlife vascular risk factors and late-life mild cognitive impairment. Neurology 2001;56: 1683-9.

10. Stewart R, Richards M, Brayne C, Mann A. Vascular risk and cognitive impairment in an older, British, African-Caribbean population. J Am Geriatr Soc 2001;49:263-9.

11. Yaffe K, Barrett-Connor E, Lin F, Grady D. Serum lipoprotein levels, statin use, and cognitive function in older women. Arch Neurol 2002;59: $378-84$.

12. Cervilla JA, Prince M, Joels S, Lovestone S, Mann A. Long-term predictors of cognitive outcome in a cohort of older people with hypertension. Br J Psychiatry 2000;177:66-71.

13. Swan GE, LaRue A, Carmelli D, Reed TE, Fabsitz RR. Decline in cognitive performance in aging twins. Arch Neurol 1992;49:476-81.

14. Benton D. Do low cholesterol levels slow mental processing. Psychosom Med 1995;57:50-3.

15. Benton D. Dietary fat and cognitive functioning. In: Hillbrand M, Spitz RT, eds. Lipids, Health, and Behavior. Washington, DC: American Psychological Association; 1997:227-43.

16. Muldoon MF, Flory JD, Ryan C. Serum cholesterol, the brain, and cognitive functioning. In: Waldstein SR, Elias MF, eds. Neuropsychology of Cardiovascular Disease. Mahwah, NJ; 2001:37-59.

17. Muldoon MF, Ryan CM, Matthews KA, Manuck SB. Serum cholesterol and intellectual performance. Psychosomatic Med 1997;59:382-7.

18. Henderson VW, Guthrie JR, Dennerstein L. Serum lipids and memory in a population based cohort of middle age women. J Neurol Neurosurg Psychiatry 2003;74:1530-5. 
19. Elias MF, Elias PK, D’Agostino RB, Silbershatz H, Wolf PA. Role of age, education and gender on cognitive performance in the Framingham Heart Study: community-based norms. Exp Aging Res 1997;23:201-35.

20. Kahn HA, Dawber TR. The development of coronary heart disease in relation to sequential biennial measures of cholesterol in the Framingham Study. J Chronic Dis 1966;19:611-20.

21. Frishman WH, Ooi WL, Derman MP, Eder HA, Gidez LI, Ben-Zeev D, Zimetbaum P, Heiman M, Aronson M. Serum lipids and lipoproteins in advanced age: intraindividual changes. Ann Epidemiol 1992;2:43-50.

22. Bookstein L, Gidding SS, Donovan M, Smith FA. Day-to-day variability of serum cholesterol, triglyceride, and high-density lipoprotein cholesterol levels. Impact on the assessment of risk according to the National Cholesterol Education Program guidelines. Arch Intern Med 1990;150: 1583-5.

23. National Cholesterol Education Program (NCEP) Expert Panel on Detection, Evaluation, and Treatment of High Blood Cholesterol in Adults (Adult Treatment Panel II): Executive Summary. NIH Publication No. 01-3670, National Heart, Lung, and Blood Institute, National Institutes of Health; 2001.

24. Jick H, Zornberg GL, Jick SS, Seshardri S, Drachman DA. Statins and the risk of dementia. Lancet 2000;356:1627-31.

25. Solfrizzi V, Panza F, Torres F, Mastroianni F, Del Parigi A, Venezia A, Capurso A. High monounsaturated fatty acids intake protects against age-related cognitive decline. Neurology 1999;12:1563-9.

26. Wardle J, Rogers P, Judd P, Taylor MA, Rapoport L, Green M, Perry KN. Randomized trial of the effects of cholesterol-lowering dietary treatment on psychological function. Am J Med 2000;108:547-53.

27. Lezak MD. Neuropsychological Assessment, $3^{\text {rd }}$ ed. New York: Oxford University Press; 1995.

28. Timm NH, Mieczkowski TA. Univariate and Multivariate General Linear Models: Theory and Applications Using SAS Software. Cary, NC: SAS Institute Inc; 1997.

29. Lamar M, Zonderman AB, Resnick S. Contribution of specific cognitive processes to executive functioning in an aging population. Neuropsychology 2002;16:156-62.

30. La Rue A. Aging and Neuropsychological Assessment. New York: Plenum Press; 1992.

31. Schretlen D, Pearlson GD, Anthony JC, Aylward EH, Augustine AM, Davis A, Barta P. Elucidating the contributions of processing speed, executive ability, and frontal lobe volume to normal age-related differences in fluid intelligence. J Int Neuropsychol Soc 2000;6:52-61.

32. Fiorenza AM, Branchi A, Sommariva D. Serum lipoprotein profile in patients with cancer. A comparison with non-cancer subjects. Int J Clin Lab Res 2000;30:141-5
33. Kaplan JR, Manuck SB, Fontenot MB, Muldoon MF, Shively CA, Mann JJ. The cholesterol-serotonin hypothesis: interrelationships among dietary lipids, central serotonergic activity, and social behavior in monkeys. In: Hillbrand M, Spitz RT, eds. Lipids, Health, and Behavior. Washington, DC: American Psychology Association; 1997:139-65.

34. Curragh EF. A proposed mechanism for memory and learning based upon very high frequency signals in the serotonergic neuronal system. J Physiol Paris 1997;91:63-7.

35. Elias MF, Elias PK, Sullivan LM, Wolf PA, D’Agostino RB. Lower cognitive function and the presence of obesity and hypertension: The Framingham Heart Study. Int J Obesity 2003;27:260-8.

36. Teunissen CE, De Vente J, von Bergmann K, Bosma H, van Boxtel MPJ, De Bruijn C, Jolles J, Steinbusch HWM, Lütjohann D. Serum cholesterol, precursors and metabolites and cognitive performance in an aging population. Neurobiol Aging 2003;24:147-55.

37. Puttonen S, Elovainio M, Kivimaki M, Lehtimaki T, KeltihangasJarvinen L. The combined effects of apolipoprotein E polymorphism and low-density lipoprotein cholesterol on cognitive performance in young adults. Neuropsychobiology 2003;48:35-40.

38. Haynes SG, Levine S, Scotch N, Feinleib M, Kannel WB. The relationship of psychosocial factors to coronary heart disease in the Framingham Study: I. Methods and risk factors. Am J Epidemiol 1978;107:362-83.

39. Boston PF, Dursun SM, Reveley MA. Cholesterol and mental disorder. Br J Psychiatry 1996;169:682-9.

40. Partonen T, Haukka J, Virtamo J, Taylor RR, Lonnqvist J. Association of low serum total cholesterol with major depression and suicide. Br J Psychiatry 1999;175:259-62.

41. Maes M, Delanghe J, Meltzer H, Scharpe S, D’Hondt P, Cosyns P. Lower degree of esterification of serum cholesterol in depression: relevance for depression and suicide research. Acta Psychiatr Scand 1984;90:252-3.

42. Lacerda AL, Caetano D, Caetano SC. Cholesterol levels in panic disorder, generalized anxiety disorder and major depression. Ar Qneuropsiquiatr 2000;58:408-11.

43. Almeida-Montes LG, Falles-Sanchez V, Moreno-Aquilar J, ChavezBalderas RA, Garcia-Marin JA, Cortes Sotres JF, Hheinze-Martin G. Relation of serum cholesterol, lipid, serotonin and tryptophan levels to severity of depression and to suicide attempts. J Psychiatry Neurosci 2000;25:371-7.

44. Jorm AF. Is depression a risk factor for dementia and cognitive decline? A review. Gerontology 2000;46:219-27.

45. Salloway S, Malloy P, Kohn R, Gillard E, Duffy J, Rogg J, Tung G, Richardson E, Thomas C, Westlake R. MRI and neuropsychological differences in early- and late-life-onset geriatric depression. Neurology 1996;46:1567-74. 